\title{
A Development of 3-D Resolution Algorithm for Aircraft Collision Avoidance
}

\section{Youngrae Kim*}

Air Force Aviation Science High School, Jinju-si, Republic of Korea

\section{Sangchul Lee ${ }^{* *}$}

School of Aerospace \& Mechanical Engineering, Korea Aerospace University, Goyang-City, Republic of Korea

\section{Keumjin Lee*** and Ja-Young Kang****}

School of Air Transportation and Logistics, Korea Aerospace University, Goyang-City, Republic of Korea

\begin{abstract}
Traffic Collision Avoidance System (TCAS) is designed to enhance safety in aircraft operations, by reducing the incidences of mid-air collision between aircraft. The current version of TCAS provides only vertical resolution advisory to the pilots, if an aircraft's collision with another is predicted to be imminent, while efforts to include horizontal resolution advisory have been made, as well. This paper introduces a collision resolution algorithm, which includes both vertical and horizontal avoidance maneuvers of aircraft. Also, the paper compares between the performance of the proposed algorithm and that of algorithms with only vertical or horizontal avoidance maneuver of aircraft.
\end{abstract}

Key words: Traffic Collision Avoidance System (TCAS), Traffic Advisory (TA), Resolution Advisory (RA), Conflict Detection and Resolution (CD\&R), Closest Point of Approach (CPA), Vertical Resolution, Horizontal Resolution, 3-Dimensional Resolution

\section{Introduction}

TCAS is designed to prevent mid-air collisions between aircraft. However, the current version of TCAS does not perform a perfect role of aircraft collision detection and avoidance, hence mid-air collisions and near misses do occasionally occur [1].

The importance of aircraft collision detection and avoidance will increase, as the demand in air traffic is projected to grow continuously. In response to the growth in air traffic demand, the Joint Planning and Development Office (JPDO) of the United States has initiated a revolutionary concept of operation, known as the Next Generation Air Transportation System (NextGen), for future air traffic operations [2]. Under the NextGen, a new concept of operation allows aircraft more flexibility in changing its flight conditions, and a part of separation responsibility is sometimes delegated to individual aircraft. As a result, the aircraft's ability for collision avoidance including TCAS should be further emphasized.

Intensive researches on collision detection and avoidance systems have been performed in the last few decades [3-8]. Prandini et al. have used a stochastic kinematic model of aircraft, with uncertainties represented by two-dimensional Brownian motion for short-term trajectory prediction [3]. Hwang et al. have proposed a probabilistic trajectory prediction algorithm, using a hybrid system aircraft dynamics model that allows various turn dynamics of aircraft to be considered, and therefore more accurate trajectory
This is an Open Access article distributed under the terms of the Creative Commons Attribution Non-Commercial License (http://creativecommons.org/licenses/by$\mathrm{nc} / 3.0 /$ which permits unrestricted non-commercial use, distribution, and reproduction in any medium, provided the original work is properly cited.

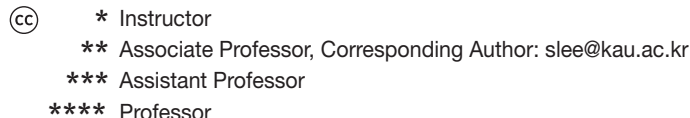


prediction and conflict detection have become possible [4]. Trapani et al. have also suggested a horizontal resolution algorithm for aircraft collision avoidance by including the bank turn dynamics of aircraft [5]. The performance of various collision avoidance algorithms have also been investigated [6-7]. More comprehensive survey on collision modeling and avoidance algorithms is provided in the reference [8].

In this paper, we introduce a new collision resolution algorithm, which includes both vertical and horizontal maneuvers of aircraft. The algorithm is considered to be the combination of vertical resolution advisory in TCAS, and horizontal resolution with the dynamics of the aircraft's bank turn. The probabilistic collision detection algorithm is also incorporated, and the performances of the proposed method were compared with those of the current TCAS vertical only algorithm in various situations.

\section{TCAS Algorithm}

TCAS is a collision detection avoidance system that prevents mid-air collision, along with structured airspace and various Air Traffic Control (ATC) procedures. The TCAS system helps pilots to visually acquire a potential threat and, if necessary, provides a last-minute collision avoidance advisory directly to the pilots [9].

The collision detection algorithm in TCAS consists of projecting aircraft's positions into the future, and identifying a potential intruder, based on several key metrics, including the estimated vertical and slant-range separations between aircraft, and the time until the closest point of approach between aircraft. Table 1 shows the criterion of Traffic Advisory (TA) and Resolution Advisory (RA). If a predicted collision is classified as TA, the TCAS issues the TA alert in the cockpit. If the situation is considered as RA, the TCAS

Table 1. Criterion of TA and RA (from reference [10])

\begin{tabular}{|c|c|c|c|c|c|c|}
\hline \multirow{2}{*}{$\begin{array}{c}\text { Own altitude } \\
(\text { feet })\end{array}$} & \multicolumn{2}{|c|}{$\begin{array}{c}\text { Tau } \\
\text { (seconds) }\end{array}$} & \multicolumn{2}{c|}{$\begin{array}{c}\text { DMOD } \\
\text { (nmi) }\end{array}$} & \multicolumn{2}{c|}{$\begin{array}{c}\text { Altitude Threshold } \\
\text { (feet) }\end{array}$} \\
\cline { 2 - 7 } & TA & RA & TA & RA & TA & RA(ALIM) \\
\hline 1000 & 20 & N/A & 0.30 & N/A & 850 & N/A \\
\hline $1000 \sim 2350$ & 25 & 15 & 0.33 & 0.20 & 850 & 300 \\
\hline $2350 \sim 5000$ & 30 & 20 & 0.48 & 0.35 & 850 & 300 \\
\hline $5000 \sim 10000$ & 40 & 25 & 0.75 & 0.55 & 850 & 350 \\
\hline $10000 \sim 20000$ & 45 & 30 & 1.00 & 0.80 & 850 & 400 \\
\hline $20000 \sim 42000$ & 48 & 35 & 1.30 & 1.10 & 850 & 600 \\
\hline$>42000$ & 48 & 35 & 1.30 & 1.10 & 1200 & 700 \\
\hline
\end{tabular}

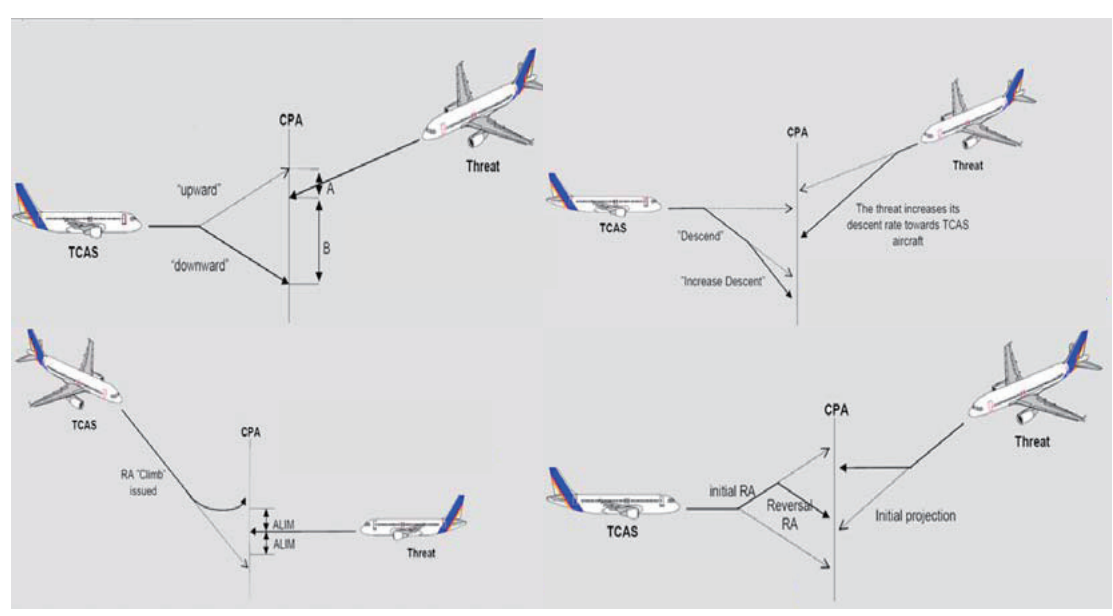

Fig. 1. State Diagram of RA (from reference [10]) 
issues not only a RA alert but also additional advisory for possible aircraft's maneuvers, as shown in Fig. 1.

\section{Modelling Of 3-D Resolution Method}

\subsection{Aircraft Dynamics}

The aircraft's horizontal and vertical positions can be expressed as

$$
\begin{aligned}
& \dot{x}=V \cos \gamma \cos \chi \\
& \dot{y}=V \cos \gamma \sin \chi \\
& \dot{h}=V \sin \gamma
\end{aligned}
$$

where, $V$ is the speed of the aircraft, $\gamma$ is the flight path angle, and $\chi$ is the heading angle of the aircraft.

The aircraft's turn dynamics can be expressed as

$$
\begin{aligned}
& R=\frac{V^{2}}{g \tan \varnothing} \\
& \Delta \chi=\frac{t \cdot g \tan \emptyset}{V} \\
& P=[x, y]=\left[x_{0}+R \operatorname{sgn}(\Delta \chi) \cdot\{\cos (\Delta \chi)-\cos (\chi+\Delta \chi)\},\right. \\
& \left.y_{0}+R \operatorname{sgn}(\Delta \chi) \cdot\{-\sin (\Delta \chi)+\sin (\chi+\Delta \chi)\}\right]
\end{aligned}
$$

where, $R$ is the turn radius, $\varnothing$ is the bank angle, $t$ is the duration of turn maneuver, and $\mathrm{P}$ is the position of the aircraft when the turn is complete.

\subsection{State Propagation and Conflict Detection}

The uncertainty levels in aircraft's each state can be expressed as follows.

$$
\begin{aligned}
& x \sim N\left(\bar{x}, \sigma_{x}\right), \quad y \sim N\left(\bar{y}, \sigma_{y}\right), h \sim N\left(h, \sigma_{h}\right) \\
& \text { where } \sigma_{x}=\sigma_{y}=\sigma_{h}=30 \mathrm{~m} \\
& V \sim N\left(\bar{V}, \sigma_{V}\right), \quad \gamma \sim N\left(\bar{\gamma}, \sigma_{\gamma}\right), \quad \chi \sim N\left(\bar{\chi}, \sigma_{\chi}\right) \\
& \text { where } \sigma_{V}=8 \mathrm{~m} / \mathrm{s}, \sigma_{\gamma}=1^{\circ}, \sigma_{\chi}=1^{\circ}
\end{aligned}
$$

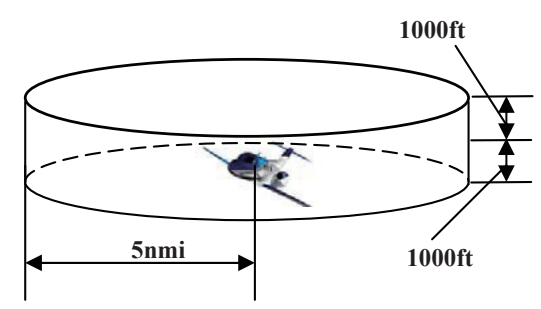

Fig. 2. Separation Standards
Equation (7) represents the uncertainty in the current location of aircraft, while the uncertainty level in the predicted position (as in Eq. (6)) can be found by translating the uncertainties in the aircraft's current speed, path angle, and heading angle into the aircraft positions, which can be found by using the Taylor expansion through Eq. (1) Eq. (3). The uncertainty levels used in Eqs. (7) (8) are practical values for a typical commercial aircraft [5]. Once we find the probabilistic expression of aircraft future locations, the probability of conflict between two aircraft can be found as follows:

$$
P_{C}=\frac{1}{2} \operatorname{erf}\left(\frac{R_{S}+\overline{r_{f}}}{\sqrt{2} \sigma_{r_{f}}}\right)+\frac{1}{2} \operatorname{erf}\left(\frac{R_{S}-\overline{r_{f}}}{\sqrt{2} \sigma_{r_{f}}}\right)
$$

where, Rs is the horizontal separation standard, and $\overline{r_{f}}$ is the relative distance between two aircraft. erf represents the error function in statistics which is given by $\operatorname{erf}(x)=(2 / \sqrt{\pi}) \int_{0}^{x} e^{-t^{2}} d t$, and $\sigma_{r f}$ represents the standard deviation of $\overline{\bar{r}_{f}}$.

\subsection{3-D Resolution Algorithm}

It is necessary to have a clear definition of a conflict. In this framework, a 'Conflict' is an event in which two or more aircraft experience a loss of minimum separation, as illustrated in Fig. 2. However, we assume that a 'Collision' means a physical confrontation of two aircraft.

If a collision is predicted by the method explained in the previous section, the aircraft turn with the bank angle of 20 degrees, and climbs (or descends) with the rate of 1500 $\mathrm{ft} / \mathrm{m}$. The 20 degrees is the typical value for aircraft's medium turn [5], and $1500 \mathrm{ft} / \mathrm{m}$ climb (or descent) rate is the value used in the current version of TCAS [6]. As future works, different values for the bank angle and the vertical rate should be adopted in the proposed algorithm. This process is illustrated by the flow chart in Fig. 3, in which Pc is the probability of conflict, and $\tau$ is the time to the Closest Point of Approach (CPA). $\mathrm{Pc}^{*}$ is a given criterion for $\mathrm{Pc}$, and $\tau^{*}$ is a

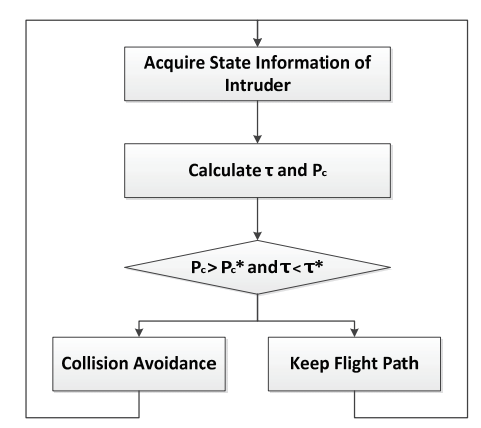

Fig. 3. 3-Dimension Resolution Flow Chart 
given criterion for $\tau$.

\section{Simulation Results}

\subsection{Resolution of Conflicts Involving Pair Aircraft}

The simulations are conducted with two situations. The first is that both aircraft go across a track. The second is that both aircraft are facing each other.

Three different collision avoidance algorithms were compared. First, we applied the algorithm in the current version of TCAS to each traffic scenario. Figures 6 13 show the simulation results. Then, we applied the collision

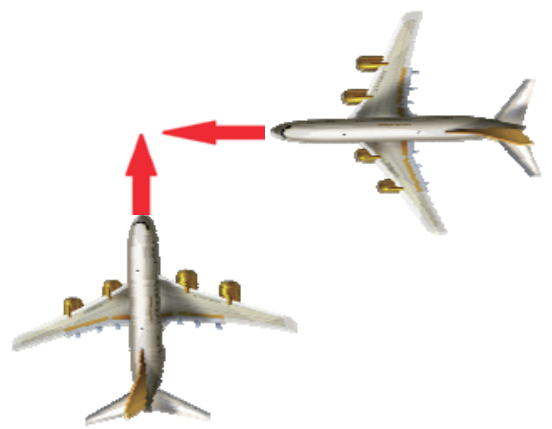

Fig. 4. Situation 1 of pair of aircraft

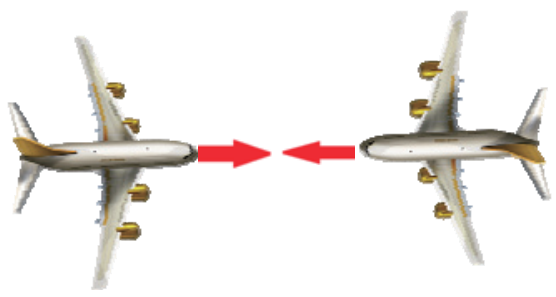

Fig. 5. Situation 2 of pair of aircraft

Table 2. Initial condition of Situation 1

\begin{tabular}{|c|c|c|}
\hline & Aircraft A & Aircraft B \\
\hline Initial & $(0,0,1)$ & $(12,12,1)$ \\
\hline Velocity & $300 \mathrm{knot}$ & $380 \mathrm{knot}$ \\
\hline Vertical & $1,500 \mathrm{ft} / \mathrm{m}$ & $1,500 \mathrm{ft} / \mathrm{m}$ \\
\hline Bank angle & $20^{\circ}$ & $20^{\circ}$ \\
\hline Heading & 000 & 270 \\
\hline
\end{tabular}

Table 3. Initial condition of Situation 2

\begin{tabular}{|c|c|c|}
\hline & Aircraft A & Aircraft B \\
\hline Initial & $(-12,12,1)$ & $(12,12,1)$ \\
\hline Velocity & $300 \mathrm{knot}$ & $380 \mathrm{knot}$ \\
\hline Vertical & $1,500 \mathrm{ft} / \mathrm{m}$ & $1,500 \mathrm{ft} / \mathrm{m}$ \\
\hline Bank angle & $20^{\circ}$ & $20^{\circ}$ \\
\hline Heading & 090 & 270 \\
\hline
\end{tabular}

TCAS Algorithm with Vertical Advisory

- Situation 1

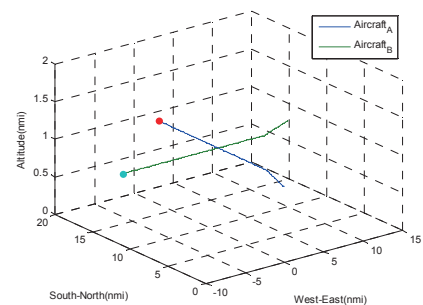

Fig. 6. Vertical resolution 3-D View

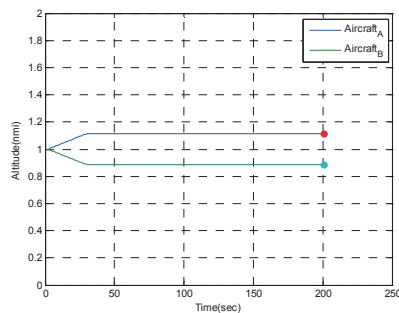

Fig. 7. Altitude of both aircraft

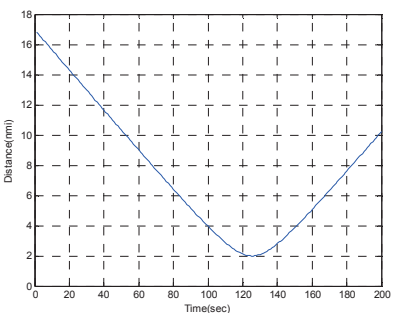

Fig. 8. Range of both aircraft

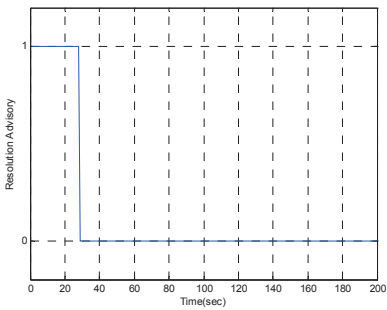

Fig. 9. Required time of resolution

\section{- Situation 2}

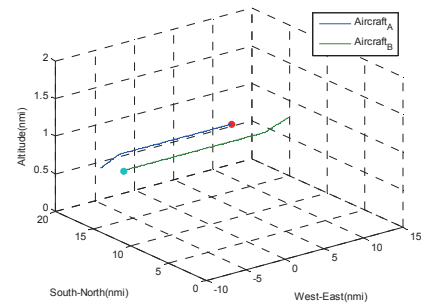

Fig. 10. Vertical resolution 3-D View 


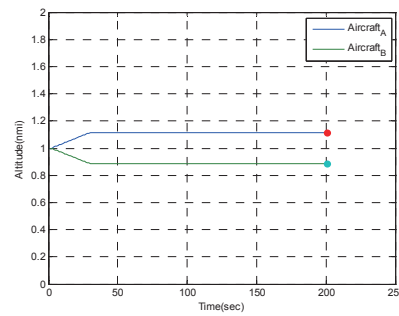

Fig. 11. Altitude of both aircraft

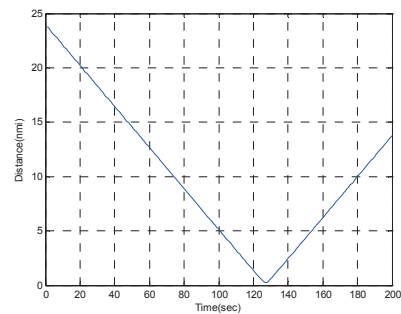

Fig. 12. Range of both aircraft

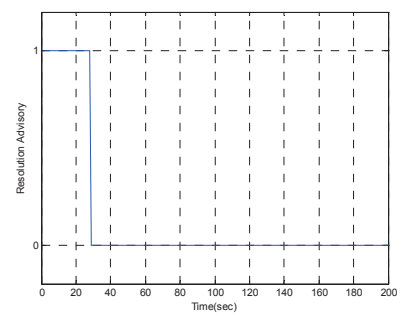

Fig. 13. Required time of resolution

\section{Horizontal Resolution Algorithm in Reference 5}

- Situation 1

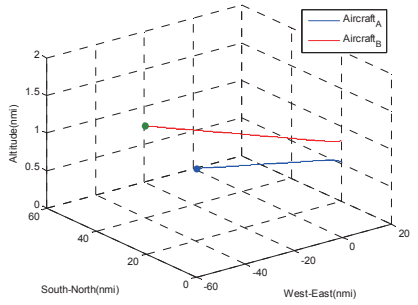

Fig. 14. Horizontal resolution 3-D view

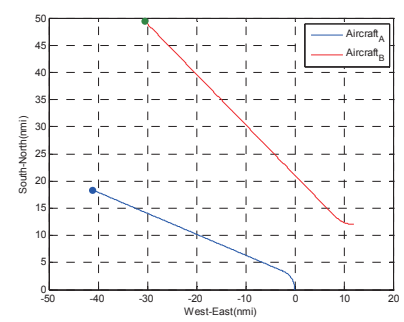

Fig. 15. Horizontal resolution top view

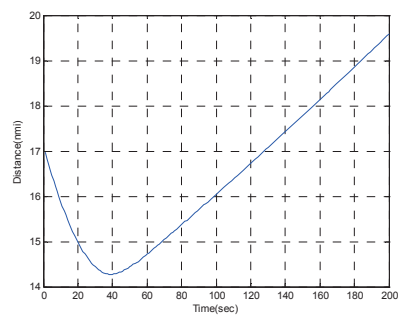

Fig. 16. Range of both aircraft

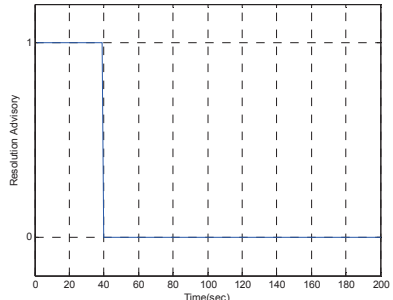

Fig. 17. Required time of resolution

\section{- Situation 2}

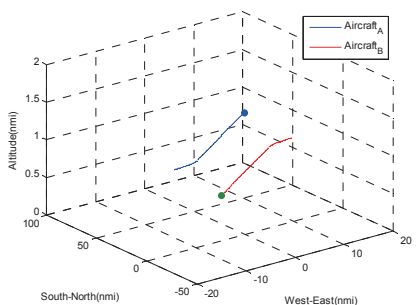

Fig. 18. Horizontal resolution 3-D view

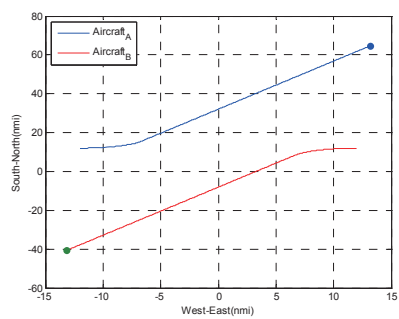

Fig. 19. Horizontal resolution top view

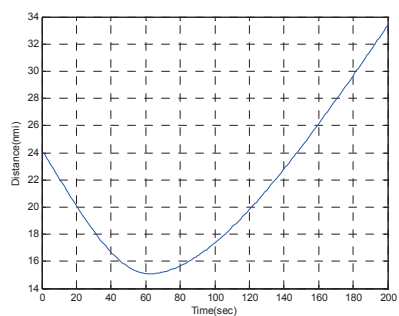

Fig. 20. Range of both aircraft 


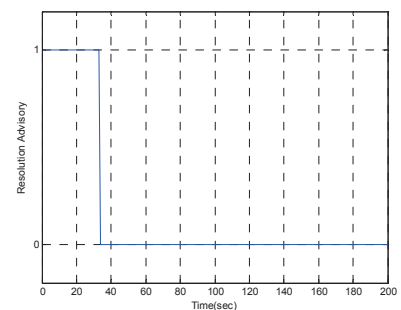

Fig. 21. Required time of resolution

\section{Proposed 3- Dimensional Resolution Algorithm}

- Situation 1

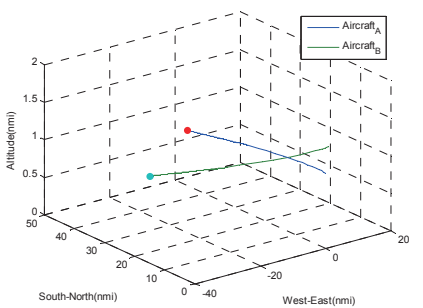

Fig. 22. 3-Dim. resolution 3-D view

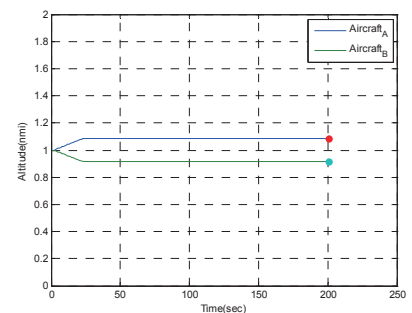

Fig. 23. Altitude of both aircraft

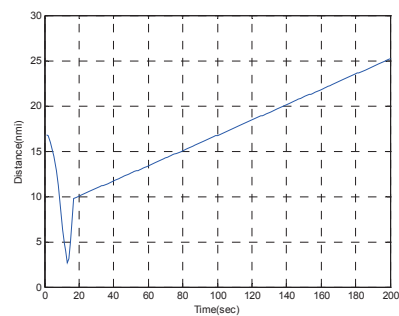

Fig. 24. Range of both aircraft

avoidance algorithm in [5], which considers only horizontal maneuver of the aircraft, by taking into account the aircraft's turn dynamics. Figures 14 21 show the simulation results. Lastly, we applied the proposed method of collision avoidance, which is the combination of the vertical resolution advisory in TCAS and the horizontal resolution with the dynamics of the aircraft's bank turn. Figures 22 29

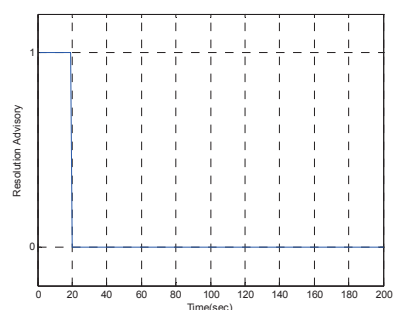

Fig. 25. Required time of resolution

\section{- Situation 2}

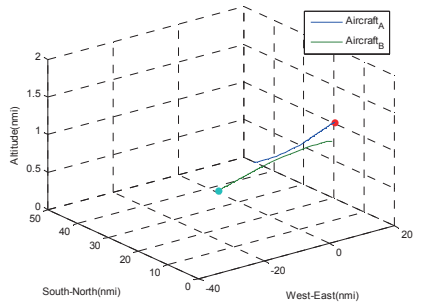

Fig. 26. 3-Dim. resolution 3-D view

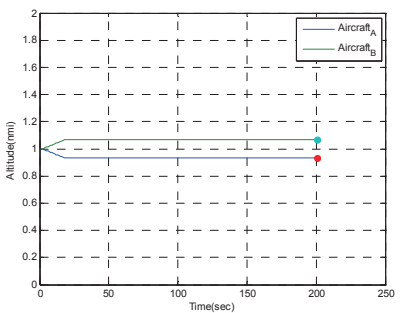

Fig. 27. Altitude of both aircraft

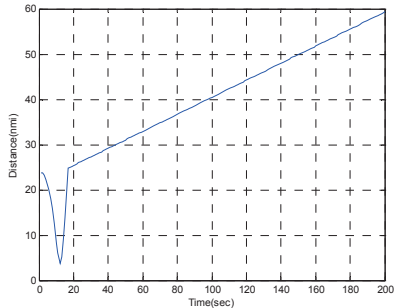

Fig. 28. Range of both aircraft

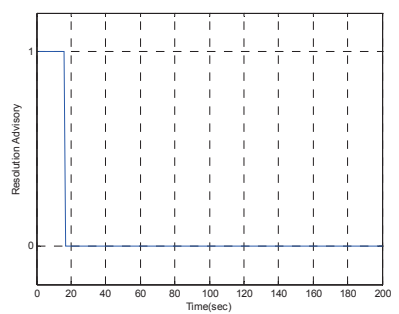

Fig. 29. Required time of resolution 
show the simulation results.

As shown in Figs. 8, 12, 16, 20, 24, and 28, the horizontal resolution algorithm could provide the largest separation between aircraft, among the three methods of collision avoidance, for both scenarios in Tables 2 and 3. However, the horizontal resolution algorithm requires the longest time of resolution, as shown in Figs. 9, 13, 17, 21, 25, and 29.

On the other hand, the TCAS algorithm only, with vertical maneuver of aircraft, provides a shorter time of resolution, but it maintains far smaller separation between aircraft than the horizontal resolution algorithm. The proposed 3-dimensional resolution algorithm could provide more balanced performances. As shown in Tables 4 and 5, the proposed algorithm requires the shortest time of resolution, while a relatively large separation between aircraft can also be maintained, compared to the two previous collision avoidance algorithms.

Each of the aircraft trajectories for the three different algorithms in both scenarios are shown in Figs. 6 7, 10 11, 14 15, 18 19, 22 23 and 26 27.

\subsection{Resolution of Conflicts Involving Multiple Aircraft}

In this section, the conflict situation with multiple aircraft is considered. 50 aircraft are involved, and the conflicts among these aircraft are resolved with the three different resolution algorithms explained in the previous sections. Table 6 is a summary of the simulation condition involving multiple aircraft. Figures 30 33, figures 34 37, and figures 38 41 show the aircraft resolution trajectories for the TCAS algorithm, the horizontal resolution algorithm, and the proposed 3-dimensional resolution algorithm, respectively.

As shown in Table 7, the greatest occurrence of RA is in the TCAS algorithm, and the smallest occurrence of RA is in the horizontal resolution algorithm. This means that the horizontal resolution algorithm can solve heavy traffic with the smallest avoidance maneuvers, compared with the others.

However, in terms of the conflicts occurred, the proposed 3-dimensional resolution algorithm has shown improved performance, i.e., a reduced number of average conflicts, compared to both the TCAS algorithm and the horizontal

Table 4. Simulation result of situation 1

\begin{tabular}{|c|c|c|c|}
\hline & TCAS & $\begin{array}{c}\text { Horizontal } \\
\text { Resolution }\end{array}$ & $\begin{array}{c}\text { 3-Dimensional } \\
\text { Resolution }\end{array}$ \\
\hline Minimum Range & $1.9968 \mathrm{nmi}$ & $14.3112 \mathrm{nmi}$ & $2.7170 \mathrm{nmi}$ \\
\hline $\begin{array}{c}\text { Minimum Vertical } \\
\text { Range }\end{array}$ & $0.2311 \mathrm{nmi}$ & $0 \mathrm{nmi}$ & $0.1656 \mathrm{nmi}$ \\
\hline $\begin{array}{c}\text { Minimum Horizontal } \\
\text { Range }\end{array}$ & $1.9834 \mathrm{nmi}$ & $14.3112 \mathrm{nmi}$ & $2.7119 \mathrm{nmi}$ \\
\hline $\begin{array}{c}\text { Required Time of } \\
\text { Resolution }\end{array}$ & $28 \mathrm{sec}$ & $38 \mathrm{sec}$ & $19 \mathrm{sec}$ \\
\hline
\end{tabular}

Table 5. Simulation result of situation 2

\begin{tabular}{|c|c|c|c|}
\hline & TCAS & $\begin{array}{c}\text { Horizontal } \\
\text { Resolution }\end{array}$ & $\begin{array}{c}\text { 3-Dimensional } \\
\text { Resolution }\end{array}$ \\
\hline Minimum Range & $0.2311 \mathrm{nmi}$ & $15.0231 \mathrm{nmi}$ & $3.7565 \mathrm{nmi}$ \\
\hline $\begin{array}{c}\text { Minimum Vertical } \\
\text { Range }\end{array}$ & $0.2311 \mathrm{nmi}$ & $0 \mathrm{nmi}$ & $0.1656 \mathrm{nmi}$ \\
\hline $\begin{array}{c}\text { Minimum Horizontal } \\
\text { Range }\end{array}$ & $0 \mathrm{nmi}$ & $15.0231 \mathrm{nmi}$ & $3.7258 \mathrm{nmi}$ \\
\hline $\begin{array}{c}\text { Required Time of } \\
\text { Resolution }\end{array}$ & $28 \mathrm{sec}$ & $33 \mathrm{sec}$ & $19 \mathrm{sec}$ \\
\hline
\end{tabular}

Table 6. Initial condition of simulation

\begin{tabular}{|c|c|}
\hline Airspace & 250nmi X 250nmi X 7nmi \\
\hline Aircraft in Airspace & 50 \\
\hline Simulation Time & $2,000 \mathrm{sec}$ \\
\hline Velocity of Aircraft & $200-400 \mathrm{knot}$ \\
\hline Multiple Conflict & Pairwise \\
\hline Responsibility of Conflict Resolution & Cooperative \\
\hline Simulation Times & 100 \\
\hline
\end{tabular}




\section{TCAS Algorithm}

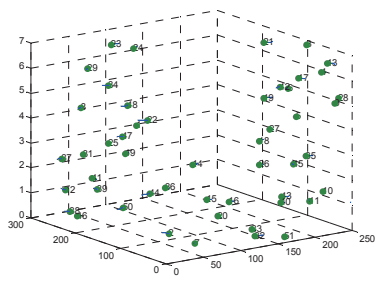

Fig. 30. 3-D view (Simulation $\mathrm{t}=100 \mathrm{~s}$ )

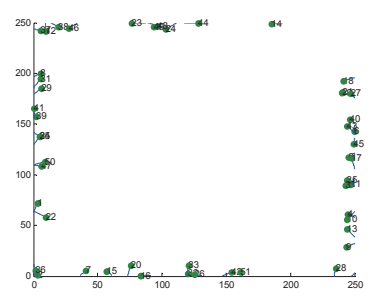

Fig. 31. Top view (Simulation $\mathrm{t}=100 \mathrm{~s}$ )

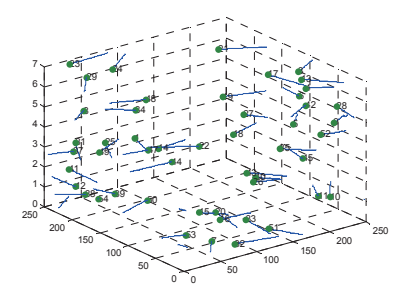

Fig. 32. 3-D view (Simulation $t=500 s$ )

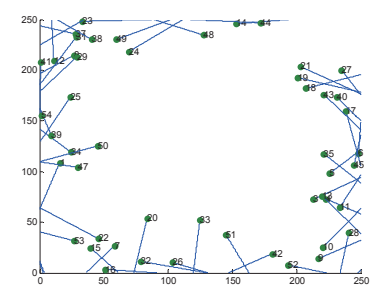

Fig. 33. Top view (Simulation $\mathrm{t}=500 \mathrm{~s}$ )

\section{Horizontal Resolution Algorithm}

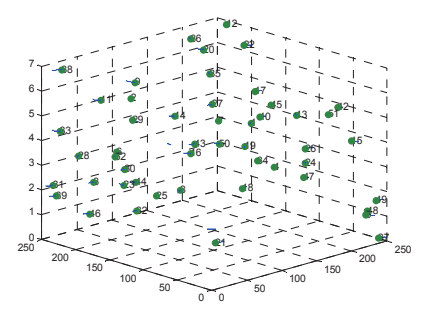

Fig. 34. 3-D view (Simulation $t=100 s$ )

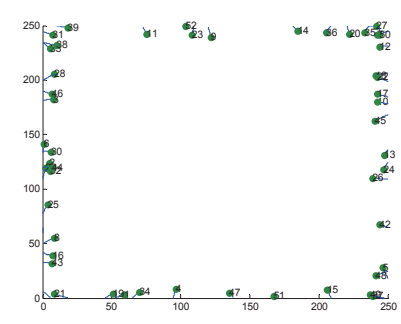

Fig. 35. Top view (Simulation $\mathrm{t}=100 \mathrm{~s}$ )

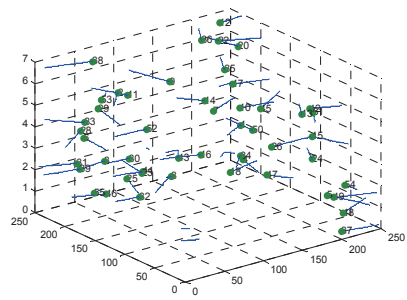

Fig. 36. 3-D view (Simulation $\mathrm{t}=500 \mathrm{~s}$ )

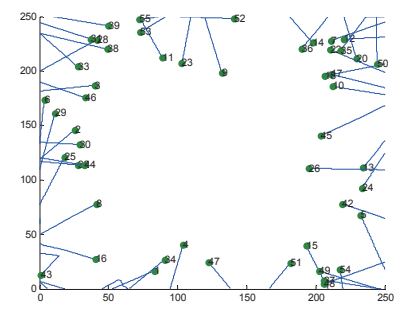

Fig. 37. Top view (Simulation $\mathrm{t}=500 \mathrm{~s}$ )

\section{Proposed 3-Dimensional Resolution Algorithm}

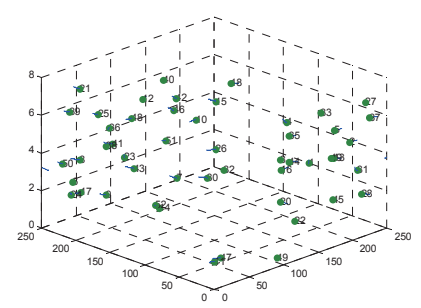

Fig. 38. 3-D view (Simulation $t=100 s$ )

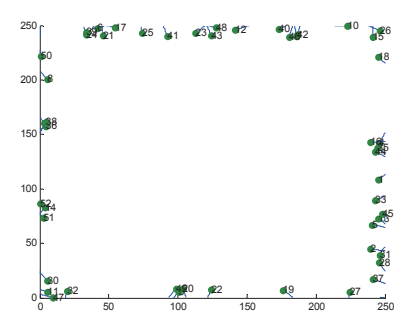

Fig. 39. Top view (Simulation $\mathrm{t}=100 \mathrm{~s}$ ) 


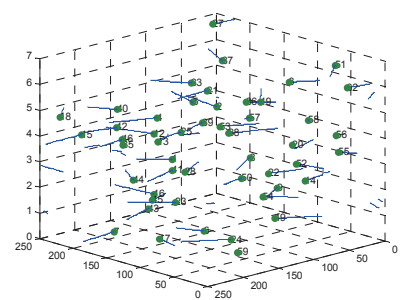

Fig. 40. 3-D view (Simulation $t=500 s$ )

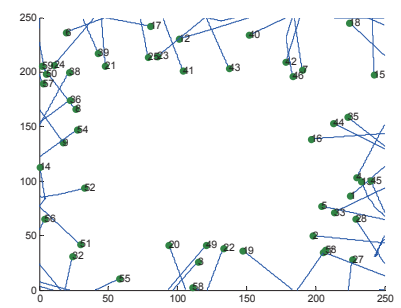

Fig. 41. Top view (Simulation $\mathrm{t}=500 \mathrm{~s}$ )

Table 7. Simulation result

\begin{tabular}{|c|c|c|c|c|}
\hline & $\begin{array}{c}\text { Average } \\
\text { Number of } \\
\text { RA }\end{array}$ & $\begin{array}{c}\text { Standard } \\
\text { Deviation of } \\
\text { RA }\end{array}$ & $\begin{array}{c}\text { Average } \\
\text { Number of } \\
\text { Conflict }\end{array}$ & $\begin{array}{c}\text { Standard } \\
\text { Deviation of } \\
\text { Conflict }\end{array}$ \\
\hline $\begin{array}{c}\text { TCAS Algorithm } \\
\begin{array}{c}\text { Horizontal } \\
\text { Resolution } \\
\text { Algorithm }\end{array}\end{array}$ & 53.99 & 9.8968 & 7.98 & 2.4535 \\
\hline $\begin{array}{c}\text { 3-Dimensional } \\
\text { Resolution } \\
\text { Algorithm }\end{array}$ & 65.46 & 7.7439 & 4.59 & 2.0305 \\
\hline
\end{tabular}

resolution algorithm. Note that no collision occurred in our simulation, but conflicts, i.e. the cases where the distance between two aircraft is less than the separation standard, did in fact occur.

\section{Conclusion}

In the paper, a 3-dimensional resolution algorithm for aircraft collision detection and avoidance is presented. The algorithm calculates the probability of collision under the presence of uncertainty in the aircraft's state variables. If the algorithm judges that a collision between aircraft is to occur, the aircraft is asked to perform avoidance maneuvers in both vertical and horizontal directions at the same time.

For verifying the performance of the algorithm, simulations with various traffic scenarios were performed. The results show that the proposed 3-dimensional resolution algorithm may provide improved performances over the other two previously proposed collision avoidance algorithms, while more extensive simulation should further be performed.

Future work should further evaluate performances of the proposed method, with traffic scenarios involving more realistic airspace environments. More study is necessary to investigate how to extend the time horizon of detecting a collision by effectively taking the aircraft's intent into account.

\section{References}

[1] Federal Aviation Administration, Accident and Incident Data.

URL : http://www.faa.gov

[2] Integrated Work Plan for the Next Generation Air Transportation System, Version FY13, Joint Planning and Development Office.

[3] Prandini, M., Hu, J., Lygeros, J., and Sastry, S., "A Probabilistic Approach to Aircraft Conflict Detection," IEEE Transactions on Intelligent Transportation Systems, Vol. 1, No. 4, 2000, pp. 199-220.

[4] Hwang, I., Hwang, J., and Tomlin, C., "Flight-ModeBased Aircraft Conflict Detection using a Residual-Mean Interacting Multiple Model Algorithm," AIAA Guidance, Navigation, and Control Conference, Austin, TX, 2003.

[5] Trapani, A., Erzberger, H., and Dunbar, W., "Performance Analysis of a Horizontal Separation Assurance Algorithm for Short-Range Conflict Detection and Resolution," AIAA Guidance, Navigation, and Control Conference, Chicago, Illinois, 2009.

[6] Ford, R. L., "The Conflict Resolution Process for TCAS II and Some Simulation Results," The Journal of Navigation, Vol. 40, Issue. 03, 2009, pp. 283-303. 
[7] Bilimoria, K. D., Lee, H. Q., Mao, Z., and Feron, E., "Comparison of Centralized and Decentralized Conflict Resolution Strategies for Multiple-aircraft Problems," AIAA Guidance, Navigation, and Control Conference, Denver, CO, 2000.

[8] Kuchar, J. K., Yang, L. C., "A Review of Conflict Detection and Resolution Modeling Methods," IEEE Transactions on Intelligent Transportation Systems, Vol. 1, No. 4, 2000, pp. 179-189.
[9] Kuchar, J. K., and Drumm, A. C., "The Traffic Alert and Collision Avoidance System," Lincoln Laboratory Journal, Vol. 16, No. 2, 2007, pp.277-296.

[10] Jun, B. K, Performance Improvement of the Collision Avoidance Algorithm for TCAS-II System with Safety Critical Software, Master Thesis, Korea Aerospace University, 2011.

[11] Paielli, R., and Erzberger, H., "Conflict Probability Estimation for Free Flight," Journal of Guidance, Control, and Dynamics, Vol. 20, No. 3, 1997, pp. 588-596. 